\title{
Root depth distribution and the diversity-productivity relationship in a long-term grassland experiment
}

Mueller, K., Tilman, D., Fornara, D., \& Hobbie, S. (2013). Root depth distribution and the diversity-productivity relationship in a long-term grassland experiment. Ecology, 94(4), 787-793. https://doi.org/10.1890/12-1399.1

Link to publication record in Ulster University Research Portal

Published in:

Ecology

Publication Status:

Published (in print/issue): 05/06/2013

DOI:

10.1890/12-1399.1

\section{Document Version}

Author Accepted version

\section{General rights}

Copyright for the publications made accessible via Ulster University's Research Portal is retained by the author(s) and / or other copyright owners and it is a condition of accessing these publications that users recognise and abide by the legal requirements associated with these rights.

\section{Take down policy}

The Research Portal is Ulster University's institutional repository that provides access to Ulster's research outputs. Every effort has been made to ensure that content in the Research Portal does not infringe any person's rights, or applicable UK laws. If you discover content in the Research Portal that you believe breaches copyright or violates any law, please contact pure-support@ulster.ac.uk. 


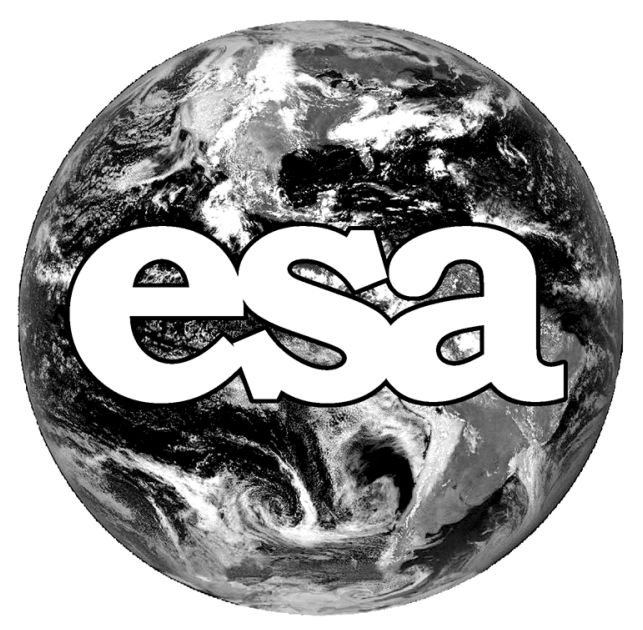

\section{ECOLOGICAL \\ SOCIETY \\ OF AMERICA}

Ecology/Ecological Monographs/Ecological Applications

\section{PREPRINT}

This preprint is a PDF of a manuscript that has been accepted for publication in an ESA journal. It is the final version that was uploaded and approved by the author(s). While the paper has been through the usual rigorous peer review process of ESA journals, it has not been copy-edited, nor have the graphics and tables been modified for final publication. Also note that the paper may refer to online Appendices and/or Supplements that are not yet available. We have posted this preliminary version of the manuscript online in the interest of making the scientific findings available for distribution and citation as quickly as possible following acceptance. However, readers should be aware that the final, published version will look different from this version and may also have some differences in content.

The doi for this manuscript and the correct format for citing the paper are given at the top of the online (html) abstract.

Once the final published version of this paper is posted online, it will replace the preliminary version at the specified doi. 
1 Running head: Diversity, rooting depth, and productivity

3 Title: Root depth distribution and the diversity-productivity relationship in a long-term grassland

4 experiment

5

6 Kevin Mueller $^{1 *}$, David Tilman ${ }^{1,2}$, Dario A. Fornara ${ }^{3}$, and Sarah E. Hobbie ${ }^{1}$

$7 \quad{ }^{1}$ University of Minnesota, Department of Ecology, Evolution and Behavior, Saint Paul, MN

8 55108, U.S.A.

$9{ }^{2}$ University of California, Bren School of the Environment, Santa Barbara, CA 93106, U.S.A.

$10{ }^{3}$ University of Ulster, School of Environmental Sciences, Coleraine, BT52 1SA, U.K.

11 * corresponding author: 100 Ecology Building, 1987 Upper Buford Circle, Saint Paul, MN 55108;

12 kevin.e.mueller@gmail.com; +1 6126255738 (phone)

13

14

15

16

17

18

19

20

21

22

23 


\section{Abstract}

25 The relationship between plant diversity and productivity in grasslands could depend, partly, on

26 how diversity affects vertical distributions of root biomass in soil; yet, no prior study has

27 evaluated the links among diversity, root depth distributions, and productivity in a long-term

28 experiment. We use data from a 12-year experiment to ask how plant species richness and

29 composition influenced both observed and expected root depth distributions of plant

30 communities. Expected root depth distributions were based on the abundance of species in each

31 community and two traits of species that were measured in monocultures: root depth

32 distributions and root to shoot ratios. The observed proportion of deep root biomass increased

33 more than expected with species richness and was positively correlated with aboveground

34 productivity. Indeed, the proportion of deep root biomass explained variation in productivity

35 even after accounting for legume presence/abundance, and greater nitrogen availability in diverse

36 plots. Diverse plots had root depth distributions that were twice as deep as expected from their

37 species composition and corresponding monoculture traits, partly due to interactions between $\mathrm{C} 4$

38 grasses and legumes. These results suggest the productivity of diverse plant communities was

39 partly dependent on belowground plant interactions that caused roots to be distributed more

40 deeply in soil.

41

42 Keywords: root biomass, aboveground biomass, complementarity, legume, C4 grass, species

43 richness, interspecific interactions 


\section{Introduction}

The positive diversity-productivity relationship in experimental grasslands is facilitated,

49 partly, by greater capture of soil resources in more diverse plant communities (Tilman et al.

50 1996, Scherer-Lorenzen et al. 2003, Spehn et al. 2005, Fornara and Tilman 2009). Several

51 factors can enhance resource acquisition in diverse plant communities, including: i) the presence

52 of nitrogen-fixing legumes (Spehn et al. 2002); ii) positive feedbacks from plant productivity and

53 plant nutrient concentrations to soil nutrient availability (Fornara and Tilman 2009, Reich et al.

54 2012); iii) high root biomass and root activity (Tilman et al. 1996, de Kroon et al. 2012); and iv)

55 niche differentiation with respect to resource requirements and extraction (Berendse 1982,

56 Mckane et al. 1990, Fargione and Tilman 2005a, von Felten et al. 2009). In this paper, we focus

57 on one related, but under-studied, factor that could greatly influence soil resource use and

58 partitioning: the vertical distribution of roots in soil.

59 The vertical distribution of roots could influence the amount and complementarity of soil

60 resource extraction in two ways. First, combinations of species with inherently different rooting

61 distributions, for example shallow and deep-rooted species, could facilitate coexistence and more

62 exhaustive use of soil resources (Berendse 1982, Mommer et al. 2010). Second, adjustments in

63 root:shoot ratios or rooting depths by one or more species in a community could facilitate

64 coexistence and increase total resource extraction. For instance, in response to depletion of

65 surface soil resources in diverse communities, some species might allocate more root biomass to

66 deep soil (Fargione and Tilman 2005b, Schenk 2008, Skinner and Comas 2010). Species in

67 diverse communities might also alter the depth distribution of roots in response to the density

68 and identity of neighboring roots (Schenk 2006, Mommer et al. 2010, de Kroon et al. 2012).

69 In this study, we explore the relationships among plant diversity, root depth distributions, 
70 and productivity using data from the $12^{\text {th }}$ year of a grassland plant diversity experiment (Tilman

71 et al. 2001). First, we evaluate how root depth distributions, at the community level, are

72 influenced by plant species richness and the presence and abundance of plants from different

73 functional groups. We then assessed the implications of community-level root depth distributions

74 for the diversity-productivity relationship. Previous studies of this experiment showed that both

75 above- and belowground plant biomass were positively correlated with plant species richness.

77 Methods

78 Study site. The experiment, located near Bethel, Minnesota (USA), was initiated in 1993

79 and planted in 1994 (Tilman et al. 2001). For the growing season, approximately May thru

80 September, the average maximum daily temperature between 1994 and 2006 was $24.4^{\circ} \mathrm{C}$, the

81 average minimum temperature was $11.7^{\circ} \mathrm{C}$, and the average precipitation was $480 \mathrm{~mm}$. Soils are

82 derived from glacial outwash and have coarse texture ( $>90 \%$ sand). Percent carbon and nitrogen

83 (N) in soil are typically lower than $1 \%$ and $0.1 \%$. The upper 6 to $8 \mathrm{~cm}$ of soil was removed prior

84 to seeding. Plots $(9 \mathrm{~m} \mathrm{x} 9 \mathrm{~m})$ were seeded to achieve five different levels of plant species

85 richness $(1,2,4,8$, and 16 species). Each level of species richness was replicated more than 25

86 times. Species composition of each plot was determined by random draws from a pool of 18

87 plant species that included four non-legume forbs (hereafter forbs), four non-woody legumes,

88 four C3 grasses, four C4 grasses, and two Quercus species. Thus, all 16-species plots contain at

89 least two species from each of the herbaceous plant types. All plots were ignited in the spring of

90 each year and weeded $\sim 3$ times per year to remove non-planted species. Following Tilman et al.

91 (2006), we focus on 152 plots that burn well and have very little Quercus biomass.

92 Sampling. In August 2006, we sampled root biomass in three different depth increments, 
$93 \quad 0-30 \mathrm{~cm}, 30-60 \mathrm{~cm}$, and 60 to $100 \mathrm{~cm}$. Three soil cores, five $\mathrm{cm}$ in diameter, were removed and

94 composited for each plot before roots were isolated from the soil by rinsing with water over a

$95 \quad 1.5-\mathrm{mm}$ mesh screen. Roots were dried at $40{ }^{\circ} \mathrm{C}$ for 10 days and weighed (Fornara and Tilman

96 2008). Aboveground biomass was sampled in August and it approximates aboveground

97 productivity due to annual spring burning (Tilman et al. 2006).

98 Estimating net adjustments of rooting depth in multi-species communities. For each plant

99 species and each rooting depth increment $(0-30,30-60$ and $60-100 \mathrm{~cm})$, we calculated the ratio of

100 root biomass to aboveground biomass using data from the monoculture plots of each species.

101 Then, for each species in a multispecies plot, the monoculture-derived root:shoot ratios were

102 multiplied by the relative aboveground abundance of that species in the mixture (i.e. the

103 proportion of total aboveground biomass attributed to that species). Finally, the calculated root

104 biomass values for each species in a plot were summed to produce an "expected" root depth

105 distribution for each plot. The expected root depth distributions reflect a null hypothesis for each

106 experimental plant community, based on the null expectation that species do not adjust their

107 root:shoot ratios or root depth distributions in response to changes in community composition or

108 resource availability. Consequently, deviations of observed root depth distributions from

109 expected values reflect adjustments in rooting depth and/or root:shoot ratios of individual species

110 that cause the root depth distribution of the whole community to become deeper, or more

111 shallow, than expected based on community composition and monoculture traits.

112 We estimated the expected root depth distributions for a subset of plots dominated by

113 species with well-characterized root depth distributions in monoculture. We defined well-

114 characterized species as those for which $>70 \%$ of aboveground biomass in monoculture plots

115 was derived from the target species. Twelve of the 16 focal species met this criterion; two C3 
116 grasses, including Poa pratensis, and two forbs did not meet this criterion. However, we have

117 confidence in our estimate of the root depth distribution of Poa pratensis monocultures because a

118 similar value, within $1 \%$ of our estimate, was observed in a neighboring experiment (P.B. Reich

119 unpublished). Expected root depth distributions were then calculated for plots where $>70 \%$ of

120 the aboveground biomass was accounted for by these thirteen species (137 out of 152 plots).

121 More and less strict cutoffs yielded similar results.

122 Statistics. All data were assessed for normality and transformed accordingly, frequently

123 using a square-root transformation. We then used ANOVA models with different combinations

124 of factors to tease out their effects on dependent variables. Type III sums of squares were used

125 for significance tests, such that the contribution of each factor was evaluated after accounting for

126 the effects of the other predictors (Hector et al. 2010). Community functional composition was

127 evaluated using binary variables coded for the presence/absence of different plant functional

128 groups (e.g. legumes, C4 grasses). To assess the effects of individual species, we used separate

129 analyses with binary variables coded for the presence/absence of each of the 13 focal species

130 (species richness was not included as a covariate). Finally, to build on previous studies that

131 identified plant $\mathrm{N}$ concentrations and soil $\mathrm{N}$ availability as important predictors of productivity in

132 our experiment (Fargione et al. 2007; Fornara \& Tilman, 2009), we compared the effect of root

133 depth distributions and N-related parameters on aboveground biomass and total root biomass in

134 additional regression models. All analyses were performed using JMP (CSAS Institute Inc.).

\section{Results}

137 Depth distribution of root biomass. Across all plots, the upper $30 \mathrm{~cm}$ of soil contained

138 between 51 and $100 \%$ of the total root biomass (sampled to a depth of $1 \mathrm{~m}$ ). Root biomass in the 
13930 to $60 \mathrm{~cm}$ and 60 to $100 \mathrm{~cm}$ depth increments showed similar patterns with species richness

140 (Fig. A1 in Appendix A) and community composition (not shown), so for statistical analyses we

141 combined these two depth increments into one: root biomass between 30 and $100 \mathrm{~cm}$.

142 Planted species richness was positively correlated with root biomass in the surface soil

$143\left(0-30 \mathrm{~cm} ; R^{2}=0.43, P<0.0001\right)$ and in the deeper soil $\left(30-100 \mathrm{~cm} ; R^{2}=0.34, P<0.0001\right)$, even after

144 accounting for variation in the presence of different functional groups (Table A1 in Appendix

145 A). Species richness had a greater positive effect on deep root biomass; the median root biomass

146 below $30 \mathrm{~cm}$ was $\sim 7$ times higher in 16-species plots than in monocultures, while the median

147 root biomass in the upper $30 \mathrm{~cm}$ of soil was $\sim 3.5$ times higher in 16 -species plots as compared to

148 monocultures. Consequently, species richness had a positive effect on the proportion of total root

149 biomass present below $30 \mathrm{~cm}$ (hereafter, the deep root proportion; $P<0.001$; Table A2; Fig. 1C).

150 The effects of plant functional composition on root biomass at different depths were

151 consistent with patterns observed in monocultures. Among monocultures, legumes had the

152 deepest rooting systems, with more than $20 \%$ of root biomass typically below $30 \mathrm{~cm}$ (Table A3).

153 Considering all plots, the presence of legumes was associated with higher root biomass in each

154 depth increment, especially in the 30 to $100 \mathrm{~cm}$ increment $(P<0.001$, Table A1), such that plots

155 with legumes had higher deep root proportions $(P<0.0001$; Table A2). For example, the deep

156 root proportion in mixtures with legumes was 3 times larger than in mixtures without legumes

157 (Fig. 1G). Contrastingly, C3 grasses had the shallowest root systems among monocultures, with

158 typically less than $1 \%$ of total root biomass occurring below $30 \mathrm{~cm}$ (Table A3). Accordingly,

159 across all plots, the presence of $\mathrm{C} 3$ grasses had negative effects on both deep root biomass

$160(P=0.01$, Table A1) and the deep root proportion ( $P<0.01$; Table A2). In monocultures, $C 4$

161 grasses and forbs had intermediate and more species-specific depth distributions of root biomass 
162 (Table A3), while across all plots the presence of $\mathrm{C} 4$ grasses and forbs had no main effect on the

163 deep root proportion (Table A2). For models of root biomass and deep root proportion, there

164 were significant interaction terms related to plant functional composition; but, species richness

165 and the main functional group effects typically explained more variation, i.e. had higher type III

166 sums-of-squares, and had smaller $P$ values (Tables A1 and A2).

$167 \quad$ Expected vs. observed root depth distributions. The differences between observed and

168 expected root depth distributions, which we expressed as differences between observed and

169 expected deep root proportions, were also related to species richness and functional composition.

170 The observed deep root proportion in the most diverse plots was two times higher than the

171 expected value ( $26 \%$ vs. $13 \% ; P<0.0001)$. The deep root proportion for plots planted with eight

172 species was $33 \%$ higher than expected $(19 \%$ vs $14 \% ; P<0.05)$, whereas observed and expected

173 deep root proportions were not significantly different for lower levels of species richness (Fig.

174 1D; significance was evaluated using paired-t tests). The co-occurrence of legumes and C4

175 grasses was strongly associated with higher deep root proportions than expected $(P \leq 0.001$; Table

176 A4). Most diverse plots contained both of these plant types, but species richness had a significant

177 effect on the deviations from expected deep root proportions even when legume and $\mathrm{C} 4$ grass

178 presence were included as covariates $(P<0.001$; Table A4). Also, when comparing among plots

179 with at least one legume and $\mathrm{C} 4$ grass present, the deviations from expected deep root

180 proportions were larger for 16-species plots than for plots with 8 or less species (Fig. 1H). The

181 presence of forbs and C3 grasses was associated with deep root proportions that were lower than

182 expected, but only when species richness was included as a covariate $(P<0.05$; Table A4).

183 Effects of individual plant species. Lupinus perennis, Lespedeza capitata and Amorpha

184 canascens each had significantly positive effects on the deep root proportion $(P<0.01)$, but the 
185 presence of Petalostemum purpureum was not a significant factor. According to calculations

186 based on model coefficients, the deep root proportion increased by $17 \%$ when Lupinus perennis

187 was present, compared to 5 and 6\% when Lespedeza capitata and Amorpha canascens were

188 present. The presence of other species did not have apparent effects on the deep root proportion.

189 The presence of Lespedeza capitata, Lupinus perennis, and Schizachyrium scoparium (a C4

190 grass) were associated with higher deep root proportions than expected $(P<0.05)$, with the

191 predicted effect sizes (using model coefficients) of Lupinus perennis and Schizachyrium

192 scoparium more than double that of Lespedeza capitata. None of the species were linked with

193 lower than expected deep root proportions based on their presence/absence.

195 richness, both aboveground and belowground biomass were positively correlated with deep root

196 proportion $\left(R^{2}=0.31\right.$ and 0.24 , respectively, $\left.P<0.0001, n=152\right)$ and with the difference between

197 observed and expected deep root proportions $\left(R^{2}=0.19\right.$ and 0.37 , respectively, $\left.P<0.0001, n=137\right)$.

198 Since deep root proportions were strongly positively correlated with the differences between

199 observed and expected deep root proportions $\left(R^{2}=0.57, P<0.0001, n=137\right)$, we focused on deep

200 root proportions in multiple regression analyses of aboveground biomass. These analyses show

201 that deep root proportion explains variance in aboveground biomass that is not accounted for by

202 planted species richness, legume presence, legume abundance, or various parameters related to $\mathrm{N}$

203 availability, including root $\mathrm{N}$ content, total soil $\mathrm{N}$, extractable soil nitrate, and the rate of net $\mathrm{N}$

204 mineralization (Table 1). This apparent effect of deep root proportion on aboveground biomass is

205 not simply a result of the correlation between deep root proportion and total root biomass, since

206 both deep root proportion and total root biomass were significant predictors of aboveground

207 biomass when included in multiple regression models $(P<0.05$, regardless of whether other 
208 predictors discussed above were included or excluded). When compared to the N-related

209 parameters, deep root proportion explained as much or more variance in aboveground biomass,

210 according to sums-of-squares, and had an effect size that was as large or larger, according to $t$

211 values and standardized model coefficients (Bring 1994) (Table 1). Results were similar for

212 regression models of total root biomass that used the difference between observed and expected

213 deep root proportions as a predictor instead of the observed deep root proportion; deviations

214 from expected deep root proportions explained variation in root biomass that was not accounted

215 for by species richness, legume presence or abundance, or N-related parameters (not shown).

217 Discussion

218 In this experiment, the most diverse and productive plant communities also had the

219 deepest distributions of root biomass (Fig. 1A-C, E-G). The relationship between diversity and

220 deep root proportion arose, not because diverse plant communities contained a higher proportion

221 of deep-rooted species, but because of plasticity in root biomass allocation in diverse

222 communities. This conclusion is supported by trends in the difference between observed and

223 expected root depth distributions (Fig. 1D,H). In plant communities with less than 8 species,

224 observed deep root proportions were similar to expected values based on the relative abundance

225 of species and the rooting characteristics of those species in monoculture (i.e. root depth

226 distributions and root:shoot ratios). However, communities with 8 or more plant species had

227 higher deep root proportions than expected, reflecting the net effect of adjustments to rooting

228 depth and/or root:shoot ratios by one or more plant species. Furthermore, the covariance of root

229 depth distributions and plant biomass, both above and belowground, depended not only on plant

230 species richness, but also on the presence of different plant functional groups (Fig. 1E-H). 
Collectively, our results suggest that diversity-dependent shifts in rooting depth, which were enhanced by plasticity in root allocation, contribute to the positive diversity-productivity

233 relationship in this experimental grassland. We hypothesize that deeper root distributions (at the

234 community level) enhanced plant productivity by enabling three related attributes of plant

235 communities to increase, including: i) spatial complementarity among species, ii) biomass of

236 absorptive roots, and iii) uptake of limiting resources in soils. To test this hypothesis requires

237 data on the distribution of root biomass for each species in a community (e.g. Mommer et al.

238 2010) and uptake of resources from different soil depths (e.g. Kulmatiski and Beard 2012).

239 Notably, even after we accounted for root depth distributions and other factors underlying

240 the diversity-productivity relationship at our site, such as legume presence and $\mathrm{N}$ availability

241 (Fornara and Tilman, 2009), species richness explained additional variance in aboveground

242 productivity. Therefore, other, unidentified factors likely contributed to the higher productivity

243 of diverse plots, such as the amelioration of pathogen effects (Maron et al. 2011, Schnitzer et al.

244 2011, de Kroon et al. 2012) or phenological complementarity (Fargione and Tilman 2005a).

245 Why do more diverse communities have deeper root distributions? The presence of

246 legumes was strongly associated with deep root depth distributions, but several lines of evidence

247 suggest the positive effects of species richness on the deep root proportion were not simply due

248 to the presence or dominance of deep-rooting legumes in diverse plots. First, species richness

249 still explained variation in root depth distributions after accounting for legume presence or

250 abundance (Table A2). Second, root depth distributions of the most diverse plots were deeper

251 than expected according to species' abundance and monoculture traits (Fig. 1D,H). Finally, for

252 plots planted with 16 species, the plots with the lowest abundance of legumes (aboveground) had

253 the deepest root depth distributions and the most apparent plasticity in root allocation (Fig. A2). 
254 Below, we discuss how interspecific interactions and the presence of particular species might

255 explain the residual effects of species richness on root depth distributions (i.e. the effects of

256 species richness that cannot be explained by the presence or abundance of legumes).

257 What caused root allocation to be more plastic in diverse plots? Only communities with

258 both legumes and $\mathrm{C} 4$ grasses consistently had deeper root depth distributions than expected

259 according to monoculture traits (Fig. 1H); these communities also had the most root biomass

260 (Fig. 1F). One possible explanation for this apparent plasticity in root allocation is that $\mathrm{C} 4$

261 grasses might grow and maintain more deep roots if legumes increased $\mathrm{N}$ availability in deep

262 soils, through both $\mathrm{N}$-fixation and mineralization of $\mathrm{N}$ in dead, $\mathrm{N}$-rich legume roots. Earlier

263 studies documented that plant productivity in this experiment increased when both legumes and

264 C4 grasses were present, but explanations of this interaction focused on the complementarity of

265 relatively fixed, inherent traits. For example, compared to $\mathrm{C} 3$ grasses and forbs, the extensive

266 root systems and low $\mathrm{N}$ tissues of $\mathrm{C} 4$ grasses probably allow greater uptake of legume-derived $\mathrm{N}$

267 and more efficient conversion of this N into biomass (HilleRisLambers et al. 2004, Fargione and

268 Tilman 2005b, Fargione and Tilman 2006, Fargione et al. 2007, Fornara and Tilman 2008). In

269 this study, we show that plasticity of root allocation could, through unknown mechanisms, also

270 contribute to the effect of legumes and $\mathrm{C} 4$ grasses on plant biomass, particularly belowground.

271 Effects of individual species. When using the presence or abundance of plant functional

272 groups as predictors of plant biomass, some of the variance in biomass that is attributed to

273 species richness could be accounted for by strong impacts of individual species within functional

274 groups. In our study, Lupinus perennis had the highest relative abundance of the legumes, the

275 largest effect of any species on the deep root proportion, and a large effect on plasticity in root

276 allocation. This is likely attributable not only to the abundance of Lupinus perennis, but also to 
277 its possession of one or more unique traits relative to other legumes. For example, Lupinus

278 perennis is the only legume species that actively grows in early spring. Since Lupinus perennis

279 was planted in nearly all of the most diverse plots ( 33 of 35 plots), its presence likely contributed

280 to the effects of planted species richness on the deep root proportion.

281 The presence of the $\mathrm{C} 4$ grass Schizachyrium scoparium in multispecies communities was

282 also associated with deeper than expected root biomass distributions. Schizachyrium scoparium

283 is a shallow rooting species in monoculture (Table A3) with a strong ability to reduce shallow

284 soil nutrient concentrations (Fargione and Tilman 2005a), two characteristics that might induce

285 co-occurring species to shift allocation of root biomass to deeper soil horizons.

286 How do our results relate to theory and results from other studies? Investment in deep

287 roots is expected to be more advantageous when shallow soil horizons reach low levels of

288 nutrient or water availability as compared to deep soil horizons (Schenk 2008, Mommer et al.

289 2010, Skinner and Comas 2010). Alternatively, some species might root more deeply in response

290 to changes in the presence or density of roots from conspecifics or other plant species (Schenk

291 2006, Mommer et al. 2010), regardless of nutrient gradients (de Kroon et al. 2012). More data on

292 species-level rooting patterns, nutrient gradients, and nutrient uptake from different depths is

293 required to distinguish among these different possibilities. The limited data we have suggests a

294 potential role for nutrient gradients; nitrate concentrations in upper soil horizons were negatively

295 correlated with species richness $\left(P<0.0001, R^{2}=0.17\right.$, using nitrate concentrations sampled in

296 mid-August 2006; see also Fargione and Tilman (2005b) and soil moisture in the upper $20 \mathrm{~cm}$ of

297 soil was depleted by the presence of legumes (not shown; see also Fornara and Tilman 2009).

298 Earlier studies of pasture forage species, including legumes, also found that root depth

299 distributions were deeper and plant productivity was higher for more diverse plant mixtures 
300 (Skinner et al. 2004, Skinner et al. 2006, Skinner and Comas 2010). Yet, because the most

301 diverse plots contained species that were not present in any replicate of lower diversity plots, the

302 apparent richness effect is difficult to evaluate (Sanderson et al. 2004). Other field and laboratory

303 experiments have observed that the depth distribution of root biomass did not increase with plant

304 species richness (Bessler et al. 2009, Wacker et al. 2009, Mommer et al. 2010). There are several

305 reasons that could explain the contrasting results of these studies: i) the absence of legumes

306 (Mommer et al, 2010) or the low levels of species richness ( $\leq 6$ species; Wacker et al. 2009;

307 Mommer et al. 2010) in some studies, ii) use of soils that are more nutrient rich than our study

308 site (Bessler et al. 2009), fertilized soils (Wacker et al. 2009), or soils that do not have realistic

309 vertical resource gradients (Mommer et al. 2010), and iii) differences among studies with respect

310 to how species richness and functional composition influence soil resource gradients. For

311 example, at an experiment in Jena, Germany that has a comparable design to our experiment, $\mathrm{N}$

312 availability in soil is generally higher and diverse plots did not reduce nitrate concentrations in

313 soil after the first year (Oelmann et al. 2011); thus, increases in aboveground biomass with

314 species richness might be supported without additional investment in root biomass, evident in

315 reduced root to shoot biomass ratios (Bessler et al. 2009).

316 Conclusions. In this 12-year-long experiment, the most productive and diverse plant

317 communities had the deepest distributions of root biomass, partly as a consequence of plasticity

318 in root allocation that arose when both legumes and $\mathrm{C} 4$ grasses were present. Future studies

319 should address the role of root depth distribution and belowground plasticity in other grassland

320 diversity experiments. Additional research is also needed to evaluate whether spatial

321 complementarity and uptake of soil resources were enhanced in diverse plots by root plasticity. 


\section{Acknowledgements}

324 We acknowledge funds from the program for Long-Term Ecological Research (U.S. N.S.F.)

325 Forest Isbell, Andrew Kulmatiski, and one anonymous reviewer provided useful comments.

\section{Literature cited}

328 Berendse, F. 1982. Competition between Plant-Populations with Different Rooting Depths III.

$329 \quad$ Field Experiments. Oecologia 53:50-55.

330 Bessler, H., V. M. Temperton, C. Roscher, N. Buchmann, B. Schmid, E. D. Schulze, W. W.

331 Weisser, and C. Engels. 2009. Aboveground overyielding in grassland mixtures is associated

332 with reduced biomass partitioning to belowground organs. Ecology 90:1520-1530.

333 Bring, J. 1994. How to Standardize Regression-Coefficients. American Statistician 48:209-213.

334 de Kroon, H., M. Hendriks, J. van Ruijven, J. Ravenek, F. M. Padilla, E. Jongejans, E. J. W.

335 Visser, and L. Mommer. 2012. Root responses to nutrients and soil biota: drivers of species

336 coexistence and ecosystem productivity. Journal of Ecology 100:6-15.

337 Fargione, J. and D. Tilman. 2005a. Niche differences in phenology and rooting depth promote

338 coexistence with a dominant C-4 bunchgrass. Oecologia 143:598-606.

339 Fargione, J. and D. Tilman. 2006. Plant species traits and capacity for resource reduction predict

340 yield and abundance under competition in nitrogen-limited grassland. Functional Ecology

$341 \quad 20: 533-540$.

342 Fargione, J., D. Tilman, R. Dybzinski, J. HilleRisLambers, C. Clark, W. S. Harpole, J. M. H.

343 Knops, P. B. Reich, and M. Loreau. 2007. From selection to complementarity: shifts in the

344 causes of biodiversity-productivity relationships in a long-term biodiversity experiment.

345 Proceedings of the Royal Society B-Biological Sciences 274:871-876. 
346 Fargione, J. E. and D. Tilman. 2005b. Diversity decreases invasion via both sampling and

347 complementarity effects. Ecology Letters 8:604-611.

348 Fornara, D. A. and D. Tilman. 2008. Plant functional composition influences rates of soil carbon

349 and nitrogen accumulation. Journal of Ecology 96:314-322.

350 Fornara, D. A. and D. Tilman. 2009. Ecological mechanisms associated with the positive

351 diversity-productivity relationship in an N-limited grassland. Ecology 90:408-418.

352 Hector, A., S. von Felten, and B. Schmid. 2010. Analysis of variance with unbalanced data: an

353 update for ecology \& evolution. Journal of Animal Ecology 79:308-316.

354 HilleRisLambers, J., W. S. Harpole, D. Tilman, J. Knops, and P. B. Reich. 2004. Mechanisms

355 responsible for the positive diversity-productivity relationship in Minnesota grasslands.

356 Ecology Letters 7:661-668.

357 Kulmatiski, A. and K.H. Beard. 2012. Root niche partitioning among grasses, saplings, and trees

358 measured using a tracer technique. Oecologia in press: DOI 10.1007/s00442-012-2390-0

359 Maron, J. L., M. Marler, J. N. Klironomos, and C. C. Cleveland. 2011. Soil fungal pathogens and

360 the relationship between plant diversity and productivity. Ecology Letters 14:36-41.

361 Mckane, R. B., D. F. Grigal, and M. P. Russelle. 1990. Spatiotemporal Differences in N-15

362 Uptake and the Organization of an Old-Field Plant Community. Ecology 71:1126-1132.

363 Mommer, L., J. van Ruijven, H. de Caluwe, A. E. Smit-Tiekstra, C. A. M. Wagemaker, N. J.

364 Ouborg, G. M. Bogemann, G. M. van der Weerden, F. Berendse, and H. de Kroon. 2010.

365 Unveiling below-ground species abundance in a biodiversity experiment: a test of vertical

366 niche differentiation among grassland species. Journal of Ecology 98:1117-1127.

367 Oelmann, Y., N. Buchmann, G. Gleixner, M. Habekost, C. Roscher, S. Rosenkranz, E. D.

368 Schulze, S. Steinbeiss, V. M. Temperton, A. Weigelt, W. W. Weisser, and W. Wilcke. 2011. 
Plant diversity effects on aboveground and belowground $\mathrm{N}$ pools in temperate grassland ecosystems: Development in the first 5 years after establishment. Global Biogeochemical

371 Cycles 25:11.

372 Reich, P. B., D. Tilman, F. Isbell, K. E. Mueller, S. E. Hobbie, D. Flynn, and N. Eisenhauer.

373 2012. Impacts of biodiversity loss escalate through time as redundancy fades. Science

$374 \quad 336: 589-592$.

375 Sanderson, M. A., R. H. Skinner, D. J. Barker, G. R. Edwards, B. F. Tracy, and D. A. Wedin.

376 2004. Plant Species Diversity and Management of Temperate Forage and Grazing Land

377 Ecosystems. Crop Science 44:1132-1144.

378 Schenk, H. J. 2006. Root competition: beyond resource depletion. Journal of Ecology 94:725-

$379 \quad 739$.

380 Schenk, H. J. 2008. The shallowest possible water extraction profile: A null model for global

381 root distributions. Vadose Zone Journal 7:1119-1124.

382 Scherer-Lorenzen, M., C. Palmborg, A. Prinz, and E.-D. Schulze. 2003. The role of plant

383 diversity and composition for nitrate leaching in grasslands. Ecology 84:1539-1552.

384 Schnitzer, S. A., J. N. Klironomos, J. HilleRisLambers, L. L. Kinkel, P. B. Reich, K. Xiao, M. C.

385 Rillig, B. A. Sikes, R. M. Callaway, S. A. Mangan, E. H. van Nes, and M. Scheffer. 2011.

386 Soil microbes drive the classic plant diversity-productivity pattern. Ecology 92:296-303.

387 Skinner, R. H. and L. H. Comas. 2010. Root Distribution of Temperate Forage Species Subjected 388 to Water and Nitrogen Stress. Crop Science 50:2178-2185.

389 Skinner, R. H., D. L. Gustine, and M. A. Sanderson. 2004. Growth, water relations, and nutritive

$390 \quad$ value of pasture species mixtures under moisture stress. Crop Science 44:1361-1369.

391 Skinner, R. H., M. A. Sanderson, B. F. Tracy, and C. J. Dell. 2006. Above- and belowground 
productivity and soil carbon dynamics of pasture mixtures. Agronomy Journal 98:320-326.

393 Spehn, E. M., et al. 2005. Ecosystem effects of biodiversity manipulations in European

394 grasslands. Ecological Monographs 75:37-63.

395 Spehn, E. M., et al. 2002. The role of legumes as a component of biodiversity in a cross-

396 European study of grassland biomass nitrogen. Oikos 98:205-218.

397 Tilman, D., J. Hill, and C. Lehman. 2006. Carbon-negative biofuels from low-input high-

398 diversity grassland biomass. Science 314:1598-1600.

399 Tilman, D., P. B. Reich, J. Knops, D. Wedin, T. Mielke, and C. Lehman. 2001. Diversity and

400 productivity in a long-term grassland experiment. Science 294:843-845.

401 Tilman, D., D. Wedin, and J. Knops. 1996. Productivity and sustainability influenced by

402 biodiversity in grassland ecosystems. Nature 379:718-720.

403 von Felten, S., A. Hector, N. Buchmann, P. A. Niklaus, B. Schmid, and M. Scherer-Lorenzen.

4042009 . Belowground nitrogen partitioning in experimental grassland plant communities of

405 varying species richness. Ecology 90:1389-1399.

406 Wacker, L., O. Baudois, S. Eichenberger-Glinz, and B. Schmid. 2009. Effects of plant species

407 richness on stand structure and productivity. Journal of Plant Ecology 2:95-106.

408

409 APPENDIX A

410 Tables report the deep root proportion of monocultures and results of statistical models of root

411 biomass, deep root proportions, and differences between observed and expected deep root

412 proportions. Figures show root biomass for each depth increment and species richness (Fig. A1)

413 and correlations of the deep root proportion and the difference between observed and expected

414 deep root proportion with the abundance of legumes and C4 grasses in diverse plots (Fig. A2). 


\section{Tables}

416 Table 1. Multiple regression and ANCOVA models of aboveground biomass. $P$ values less than 0.001 are in bold, between 0.001 and

4170.01 are in bold italic, between 0.01 and 0.05 are in italic, and between 0.05 and 0.1 in normal print

$$
N \text { parameters only } \quad \text { N parameters \& } \% \text { deep roots } \quad N \text { par., leg. pres., \& no. of species } \quad \text { all predictors }
$$

\begin{tabular}{|c|c|c|c|c|c|c|c|c|c|c|c|c|}
\hline Factor & $\% S S^{*}$ & $t$ value & Effect size $^{\#}$ & $\% S S^{*}$ & $t$ value & Effect size $^{\#}$ & $\% S S^{*}$ & $t$ value & Effect size & $\% S S^{*}$ & $t$ value & Effect size $^{\#}$ \\
\hline initial soil N\% & 1 & 1.9 & 22 & 1 & 2.0 & 21 & 2 & 3.2 & 28 & 2 & 3.1 & 27 \\
\hline$\Delta$ soil $\mathrm{N} \%^{\dagger}$ & 6 & 4.1 & 45 & 5 & 3.8 & 39 & 2 & 3.3 & 29 & 2 & 3.3 & 28 \\
\hline$\Delta \operatorname{root} \mathrm{N} \%{ }^{\ddagger}$ & 5 & 3.6 & 44 & 3 & 3.2 & 36 & ns & ns & ns & ns & ns & ns \\
\hline net $\mathrm{N}$ mineralization & 11 & 5.3 & 73 & 4 & 3.8 & 49 & 2 & 3.0 & 34 & 1 & 2.5 & 28 \\
\hline soil $\mathrm{NO}_{3}{ }^{\text {" }}$ & 13 & -5.8 & -78 & 9 & -5.5 & -67 & 2 & -3.2 & -38 & 2 & -3.1 & -35 \\
\hline$\%$ deep roots & na & na & na & 11 & 6.0 & 69 & na & na & na & 2 & 3.3 & 35 \\
\hline no. of species & na & na & na & na & na & na & 6 & 5.3 & 65 & 6 & 5.2 & 62 \\
\hline Legume presence ${ }^{\S}$ & na & na & na & na & na & na & 9 & 6.2 & 75 & 5 & 4.8 & 59 \\
\hline$R^{2}$ & & 0.44 & & & 0.55 & & & 0.68 & & & 0.70 & \\
\hline$n$ & & 152 & & & 152 & & & 152 & & & 152 & \\
\hline
\end{tabular}

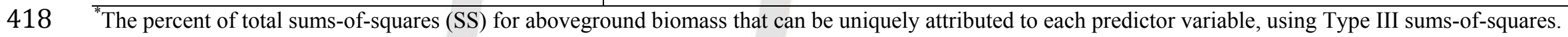

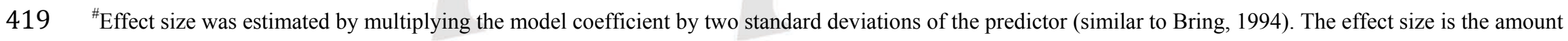

420 of aboveground biomass $\left(\mathrm{g}\right.$ per $\mathrm{m}^{2}$ ) predicted to be gained or lost when each predictor shifts from one SD below the mean to one $\mathrm{SD}$ above the mean. ${ }^{\dagger}$ The

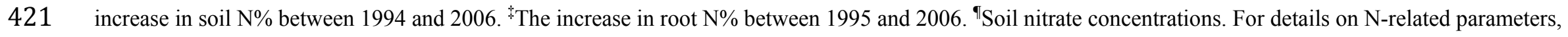

422 see Fornara and Tilman (2009). ${ }^{\S}$ Similar results were observed when using legume abundance. na $=$ not included in the model. ns $=$ not significant $(P>0.1)$. 


\section{Figure legends}

424 Figure 1. Effects of species richness and community composition on plant biomass, the deep

425 root proportion, and the difference between observed and expected deep root proportions. The

426 categories describing community composition were chosen based on results of statistical models

427 of the deep root proportion and the difference between observed and expected deep root

428 proportions (Tables A2 and A4). Error bars indicate standard error. Within each panel, bars

429 labeled with different letters are significantly different according to Tukey tests $(P<0.05)$. 

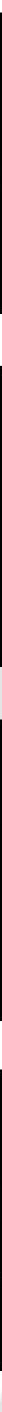

Planted species richness

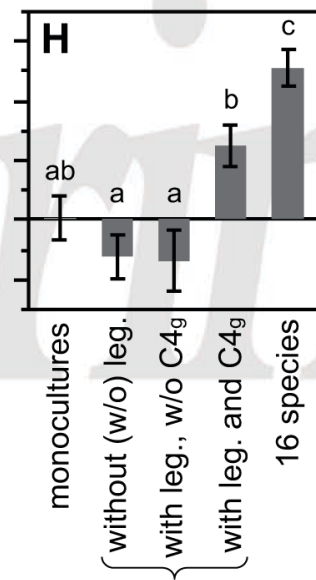

mixtures with < 16 sp. 